Issue and Deterrence" first appeared, Sakharov was in exile in Gorki; his response to these articles, which was published in the June 1983 issue of Foreign Affairs, provoked the wrath of Soviet and Communist Party officials. Sakharov was denounced as a hypocrite, accused of being a warmonger who had betrayed his motherland, and was contrasted unfavourably with "peace-defender" Drell. The most notorious article attacking Sakharov (and ostensibly in support of Drell) appeared in Izvestia on 3 July 1983 under the title "When Honour and Conscience are Lost" and was signed by four Soviet academicians. It so happened that one of us (V. I. G.) was constantly urged to go to the Communist Party Central Committee and provide the fifth signature. It was not easy to resist this persistent onslaught. As Sakharov writes in his Memoirs (Knopf, 1990), the intended fifth author "had refused [to be a signatory] saying that he'd need to get a look at [Sakharov's] article first. . . . He was told that there wasn't time for that, and so he escaped with his honor intact."

Nearly two-thirds of Drell's book cov- ers his work on arms control, a subject that he considers to be "an important part of our national security". For the past 15 years, Drell has made an independent and original examination of many armscontrol problems, including US-Soviet strategic balance, nuclear deterrence, the Strategic Defense Initiative ('Star Wars') and the testing and safety of nuclear warheads. It is his belief that "our scientific community as a whole has a special obligation to assist society to understand the implications of the products of our scientific advances and to shape the applications of those products in ways more beneficial than dangerous to the human condition". Proponents of this admirable conceit will be among the most enthusiastic readers of this wide-ranging and informative book.

Vitaliy 1. Goldanskii is in the Institute of Chemical Physics, Russian Academy of Sciences, 4 Ulitsa Kosygina, Moscow 117334, Russia; Stanislav N. Rodionov is in the Space Research Institute, Russian Academy of Sciences, 84/32 Profsoyznaya Street, Moscow 117810, Russia.

\title{
Images of cellular mechanisms
}

\section{Harold P. Erickson}

The Machinery of Life. By David S. Goodsell. Springer: 1993. Pp. 132. £25.50, \$29.

THE goal of this book is straightforward: to present scale model images of the machinery of life, including its complex macromolecules, substrates and large assemblies. The actual achievement is far grander - the drawings are among the most instructive one can find in structural biology, and the mechanisms of life are elegantly explained in only 132 pages.

The genius of the book is in its simplicity. Drawings of molecules are shown at only three magnifications: 1,10 and 30 million-fold. Structures are presented in only two styles. At the lowest magnification, protein molecules are drawn as simple outlines to give a rough idea of their size and shape: ribosomes have distinctive beaks, antibodies are Y-shaped, DNA is a rope with the pitch correctly indicated. At the higher magnifications, molecules are presented as space-filling atomic models. The consistency of this presentation makes it easy to relate the molecules in the different figures. Most of the drawings are black and white, but there are 16 beautiful colour plates of representative molecules, using red and blue to show charged atoms, green or yellow for other atomic features. The comparison of molecules is very instructive, and the relative dimensions of ATP, enzymes, DNA and ribosomes quickly become second nature.

Probably the most novel and important perspective in these drawings is to show groups of molecules at their actual concentration in vivo. That the bacterial cytoplasm is "a teeming soup of molecules" is vividly emphasized by drawings showing the jumble of mitochondria, enzymes and RNA molecues that fill 30 per cent of the cytoplasmic volume. The tangled mixture of double- and single-stranded DNA, histones and polymerases in the nuclear region is daunting. A few minutes study may be needed to overcome the feeling of claustrophobia, but will reward the reader with a lasting impression of the density and complexity of this soup of life.

The text is written as if for the nonspecialist, but will be most appreciated by readers familiar with or even expert in the basics of biochemistry. There are no chemical formulas except, for the space-filling models, no equations and only a few numbers, always interesting. Important chemical insights are stated succinctly and boldly in the text. And the most elegant mechanisms are presented in an easily accessible but constantly informative way. This is a fresh and engaging book recommended to all students of biology.

Harold P. Erickson is in the Department of Cell Biology, Duke University Medical School, Durham, North Carolina 27710, USA.

\section{Imaging Earth}

\section{B. L. N. Kennett}

Seismic Tomography. Edited by H. M. Iyer and K. Hirahara. Chapman and Hall: 1993. Pp. 842. £135, \$249.95.

METHODS of determining the threedimensional distribution of seismic wave speeds in the Earth have come to be known as 'seismic tomography' by analogy with medical imaging techniques. But the illumination of the Earth by earthquake and man-made tremors is not nearly as uniform as the illumination of the human body by X-rays. Receivers can be placed only near the Earth's surface, so considerable ingenuity is required to get good images. Most seismic tomography today is based on the times of arrival of seismic phases, but for large-scale problems the amplitude and phase information is beginning to be used.

This compilation brings together the expertise of 58 authors in 40 articles. The articles are arranged in order of decreasing scale, starting with images of the whole mantle of the Earth and finishing with mining and engineering applications. The coverage is thorough and provides an up-to-date overview of current activity. I am unsure, however, for whom the book is intended: despite its length, it is not self-contained. Nearly every section requires an extensive knowledge of seismology for maximum benefit; so although students are likely to find the book helpful, they will need substantial help to encompass all of the articles. There is also a lot of overlap in theoretical material between many of the articles; although some parts are well integrated, the notations used in different sections are not always consistent. The editors have, however, succeeded in getting a much more extensive discussion of the reliability of results than is usually encountered.

The emphasis of most of the articles is on the detailed application of leastsquares techniques for handling the arrival times of seismic waves, using iterative matrix solvers. Only a few articles look forward to suggest ways in which the quality of seismic images might be improved. As computational costs decrease, existing procedures should benefit from the inclusion of three-dimensional ray tracing. But the most dramatic improvements will probably come from careful experimental work to improve data coverage in three dimensions and from the exploitation of currently under-used information, such as the character of seismic wave forms.

B. L. N. Kennett is in the Research School of Earth Sciences, Australian National University, Canberra, ACT 0200, Australia. 